\title{
Wind Turbine Gearbox Technologies
}

\author{
Adam M. Ragheb ${ }^{1}$ and Magdi Ragheb ${ }^{2}$ \\ ${ }^{1}$ Department of Aerospace Engineering \\ ${ }^{2}$ Department of Nuclear, Plasma and Radiological Engineering, \\ University of Illinois at Urbana-Champaign, 216 Talbot Laboratory
}

USA

\section{Introduction}

The reliability issues associated with transmission or gearbox-equipped wind turbines and the existing solutions of using direct-drive (gearless) and torque splitting transmissions in wind turbines designs, are discussed. Accordingly, a range of applicability of the different design gearbox design options as a function of the rated power of a wind turbine is identified. As the rated power increases, it appears that the torque splitting and gearless design options become the favored options, compared with the conventional, Continuously Variable Transmission (CVT), and Magnetic Bearing transmissions which would continue being as viable options for the lower power rated wind turbines range.

The history of gearbox problems and their relevant statistics are reviewed, as well as the equations relating the gearing ratios, the number of generator poles, and the high speed and low speed shafts rotational speeds.

Aside from direct-drive systems, the topics of torque splitting, magnetic bearings and their gas and wind turbine applications, and Continuously Variable Transmissions (CVTs), are discussed.

Operational experience reveals that the gearboxes of modern electrical utility wind turbines at the MegaWatt (MW) level of rated power are their weakest-link-in-the-chain component. Small wind turbines at the $\mathrm{kW}$ level of rated power do not need the use of gearboxes since their rotors rotate at a speed that is significantly larger than the utility level turbines and can be directly coupled to their electrical generators.

Wind gusts and turbulence lead to misalignment of the drive train and a gradual failure of the gear components. This failure interval creates a significant increase in the capital and operating costs and downtime of a turbine, while greatly reducing its profitability and reliability. Existing gearboxes are a spinoff from marine technology used in shipbuilding and locomotive technology. The gearboxes are massive components as shown in Fig. 1.

The typical design lifetime of a utility wind turbine is 20 years, but the gearboxes, which convert the rotor blades rotational speed of between 5 and 22 revolutions per minute (rpm) to the generator-required rotational speed of around 1,000 to $1,600 \mathrm{rpm}$, are observed to commonly fail within an operational period of 5 years, and require replacement. That 20 year lifetime goal is itself a reduction from the earlier 30 year lifetime design goal (Ragheb \& Ragheb, 2010). 


\section{Gearbox issues background}

The insurance companies have displayed scrutiny in insuring wind power generation. The insurers joined the rapidly-growing market in the 1990s before the durability and long term maintenance requirements of wind turbines were fully identified. To meet the demand, a number of units were placed into service with limited operational testing of prototypes.

During the period of quick introduction rate, failures during wind turbines operation were common. These included rotor blades shedding fragments, short circuits, cracked foundations, and gearbox failure. Before a set of internationally recognized wind turbine gearbox design standards was created, a significant underestimation of the operational loads and inherent gearbox design deficiencies resulted in unreliable wind turbine gearboxes.

The lack of full accounting of the critical design loads, the non-linearity or unpredictability of the transfer of loads between the drive train and its mounting fixture, and the mismatched reliability of individual gearbox components are all factors that were identified

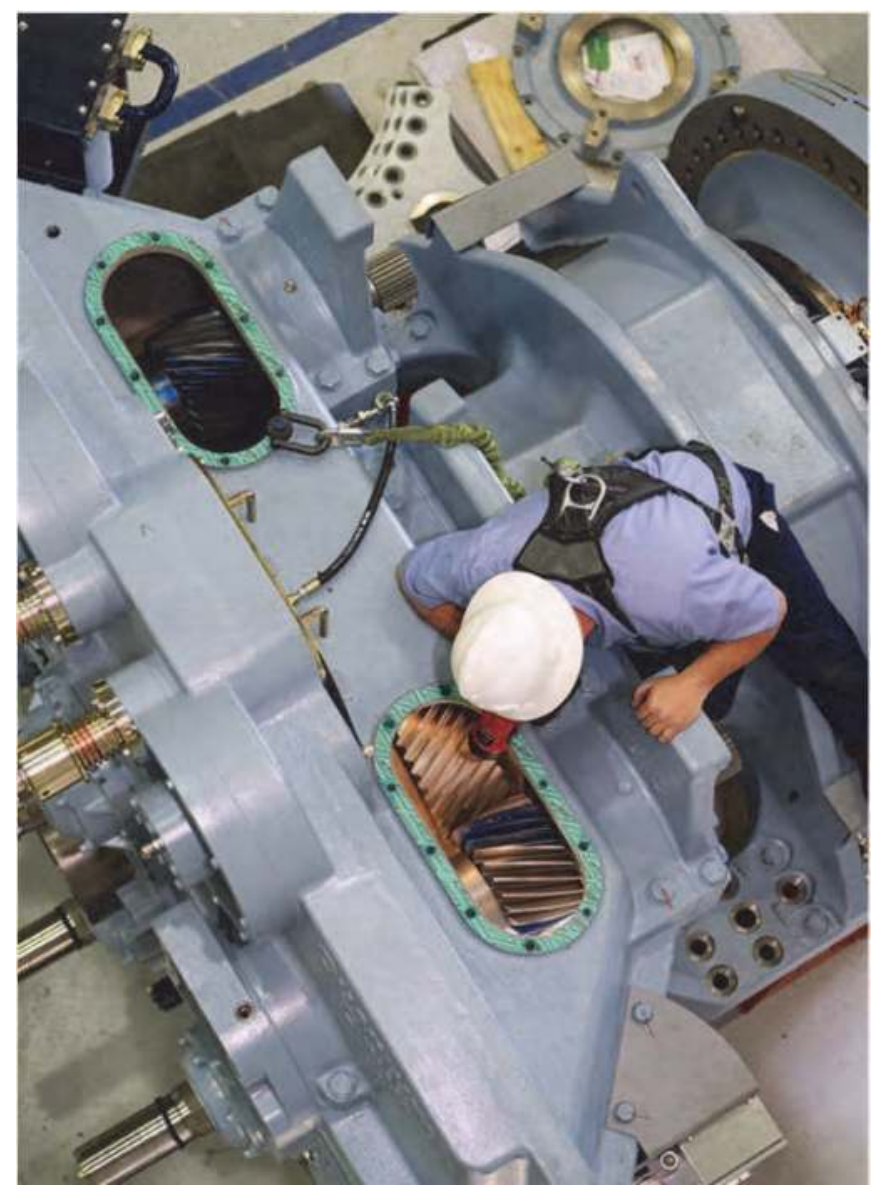

Fig. 1. Top view of a Liberty Quantum Drive 2.5 MW rated power wind turbine gearbox (Source: Clipper Windpower). 
by the National Renewable Energy Laboratory (NREL) as contributing to the reduced operating life of gearboxes (Musial et al., 2007).

In 2006, the German Allianz reportedly received 1,000 wind turbine damage claims. An operator had to expect damage to his facility at a 4-5 years interval, excluding malfunctions and uninsured breakdowns.

As a result of these earlier failures, insurers adopted provisions that require the inclusion by the operator of maintenance requirements into their insurance contracts. One of the common maintenance requirements is to replace the gearbox every 5 years over the 20-year design lifetime of the wind turbine. This is a costly task, since the replacement of a gearbox accounts for about 10 percent of the construction and installation cost of the wind turbine, and will negatively affect the estimated income from a wind turbine (Kaiser \& Fröhlingsdorf, 2007). Figure 1 depicts the size of the Quantum Drive gearbox of a Liberty 2.5 MW wind turbine (Clipper Windpower, 2010)

The failure of wind turbine gearboxes may be traced to the random gusting nature of the wind. Even the smallest gust of wind will create an uneven loading on the rotor blades, which will generate a torque on the rotor shaft that will unevenly load the bearings and misalign the teeth of the gears. This misalignment of the gears results in uneven wear on the teeth, which in turn will facilitate further misalignment, which will cause more uneven wear, and so on in a positive feedback way.

The machine chassis will move, which will misalign the gearbox with the generator shaft and may eventually cause a failure in the high speed rear gearing portion of the gearbox. Further compounding the problem of uneven rotor blade loading is the gust slicing effect, which refers to multiple blades repeatedly traveling through a localized gust (Burton et al., 2004). If a gust of wind were to require 12 seconds to travel through the swept area of a wind turbine rotor operating at $15 \mathrm{rpm}$, each of the three blades would be subject to the gust three times, resulting in the gearbox being subjected to a total of nine uneven loadings in a rapid succession.

The majority of gearboxes at the 1.5 MW rated power range of wind turbines use a one- or two-stage planetary gearing system, sometimes referred to as an epicyclic gearing system. In this arrangement, multiple outer gears, planets, revolve around a single center gear, the sun. In order to achieve a change in the rpm, an outer ring or annulus is required.

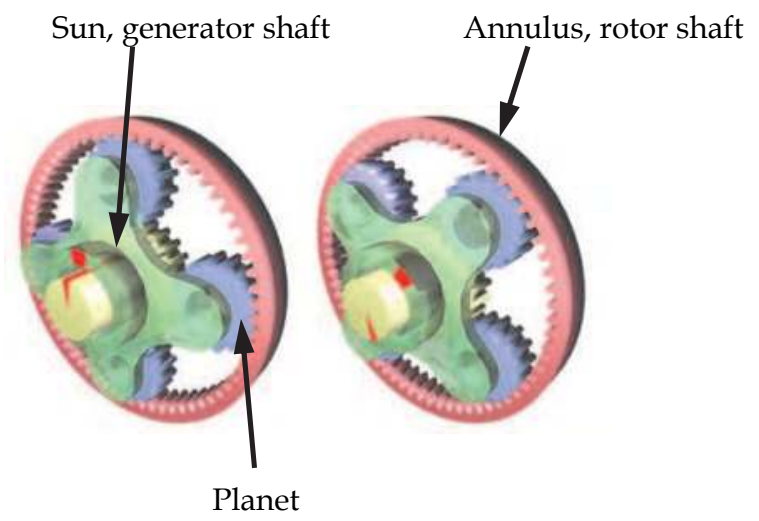

Fig. 2. Planetary gearing system. 
As it would relate to a wind turbine, the annulus in Fig. 2 would be connected to the rotor hub, while the sun gear would be connected to the generator. In practice however, modern gearboxes are much more complicated than that of Fig. 2, and Fig. 3 depicts two different General Electric (GE) wind turbine gearboxes.
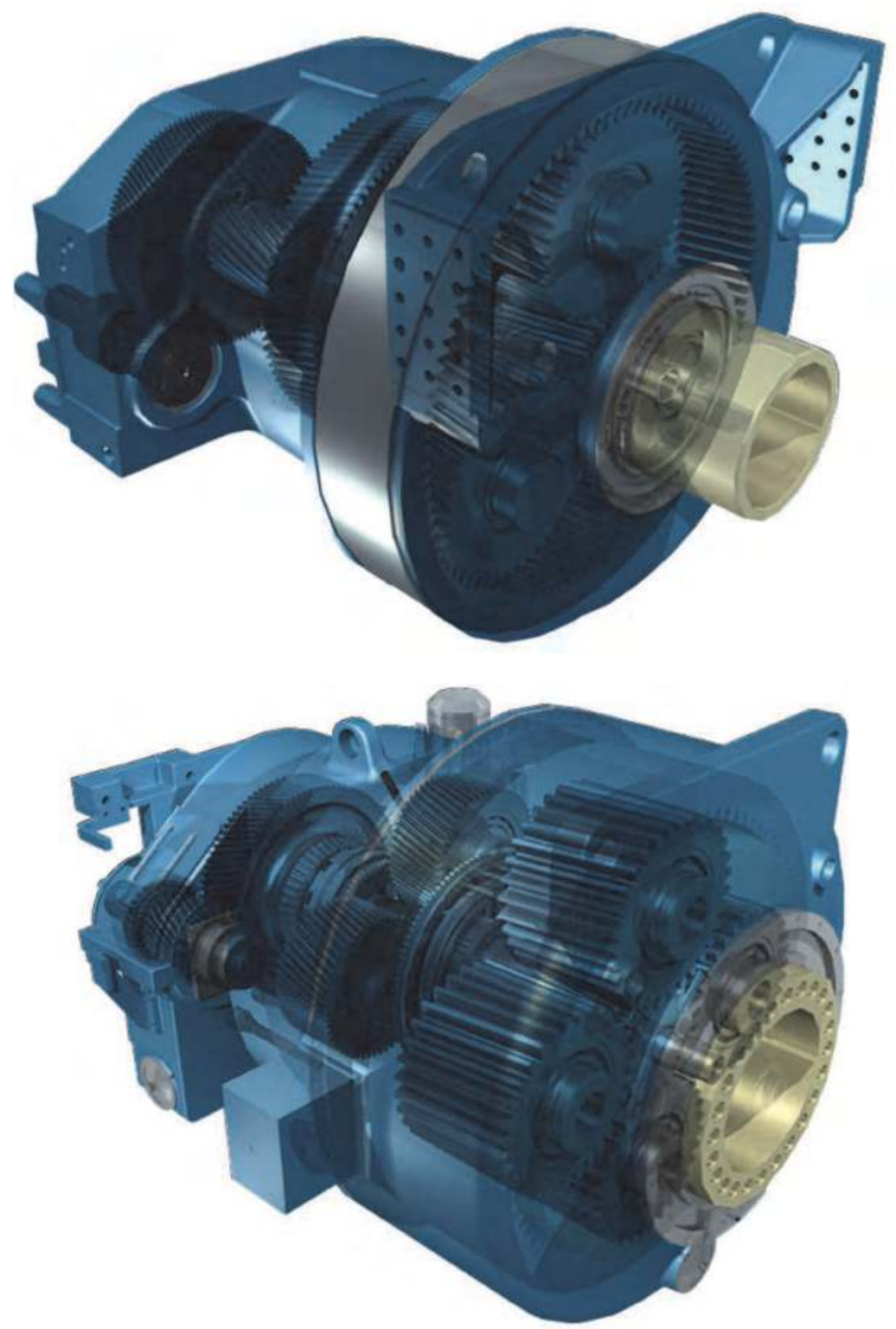

Fig. 3. GE 1P 2.3 one-stage planetary and two-stage parallel shaft (top) and 2P 2.9 two-stage planetary and one-stage parallel shaft (bottom) wind turbine gearboxes (Image: GE). 
Planetary gearing systems exhibit higher power densities than parallel axis gears, and are able to offer a multitude of gearing options, and a large change in rpm within a small volume. The disadvantages of planetary gearing systems include the need for highly-complex designs, the general inaccessibility of vital components, and high loads on the shaft bearings. It is the last of these three that has proven the most troublesome in wind turbine applications.

In order to calculate the reduction potential of a planetary gear system, the first step is to determine the number of teeth, $\mathrm{N}$, that each of the three component gears has. These values will be referred to as:

$$
N_{\text {sun }}, N_{\text {annulus }}, \text { and } N_{\text {planet }}
$$

as they relate to the number of teeth on the sun, annulus, and planet gears, respectively.

Using the relationship that the number of teeth is directly proportional to the diameter of a gear, the three values should satisfy Eqn. 1, which shows that the sun and annulus gears will fit within the annulus.

$$
N_{\text {sun }}+2 N_{\text {planet }}=N_{\text {annulus }}
$$

With Eqn. 1 satisfied, the equation of motion for the three gears is,

$$
\left(2+\frac{N_{\text {sun }}}{N_{\text {planet }}}\right) \omega_{\text {annulus }}+\frac{N_{\text {sun }}}{N_{\text {planet }}} \omega_{\text {sun }}-2\left(1+\frac{N_{\text {sun }}}{N_{\text {planet }}}\right) \omega_{\text {planet }}=0
$$

where: $\omega_{\text {sun }}, \omega_{\text {annulus, }}$ and $\omega_{\text {planet }}$ are the angular velocities of the respective gears.

Since the angular velocity and is directly proportional to the revolutions per minute (rpm), Eqn. 2 may be modified to Eqn. 3 below.

$$
\left(2+\frac{N_{\text {sun }}}{N_{\text {planet }}}\right) r p m_{\text {annulus }}+\frac{N_{\text {sun }}}{N_{\text {planet }}} r p m_{\text {sun }}-2\left(1+\frac{N_{\text {sun }}}{N_{\text {planet }}}\right) r p m_{\text {planet }}=0
$$

Known values may be substituted into Eqn. 3 in order to determine the relative rpm values of the sun and annulus gears, noting the two equalities of Eqns. 4 and 5 below (Ragheb \& Ragheb, 2010).

$$
\begin{gathered}
r p m_{\text {sun }}=\left(-\frac{N_{\text {sun }}}{N_{\text {planet }}}\right) r p m_{\text {planet }} \\
r p m_{\text {planet }}=\left(-\frac{N_{\text {planet }}}{N_{\text {annulus }}}\right) r p m_{\text {annulus }}
\end{gathered}
$$

Historically, the gearbox has been the weakest link in a modern, utility scale wind turbine. Following the current trend of larger wind turbines for offshore applications with their larger rotor diameters and heavier rotor blades, gearboxes are being subject to significantly increased loads.

Minor improvements in the gearbox lubrication and oil filtration system have increased the reliability of wind turbines, but to significantly improve the gearbox reliability, the design 
must be changed from the current planetary gear design. This improved reliability is especially important for offshore applications, as the wind turbines are generally much larger and the cost of maintenance is much greater.

\section{Gearless / direct-drive wind turbines}

The Enercon Company of Germany and ScanWind of Norway have served as the pioneers of the Gearless, or Direct-Drive, wind turbine generator. By increasing the number of magnetic pole pairs in a generator from the 4 or 6 of conventional generators to 100 or more, the need for a gearbox may be eliminated.

In order to produce the 60 or $50 \mathrm{~Hz}$ electrical power for the United States or Europe, a 4-pole generator would have to operate at 1,800 or $1,500 \mathrm{rpm}$ respectively. Increasing the number of poles to 6 would decrease the generator rpm to 1,200 and 1,000, respectively. The relationship between the generator $\mathrm{rpm}$, the number of poles $\mathrm{n}$, and the frequency $\mathrm{f}$ is given by:

$$
f=n \frac{r p m}{120}[\mathrm{~Hz}]
$$

A four-pole, 1,800 rpm generator has a frequency:

$$
f=4 \frac{1,800}{120}=60[\mathrm{~Hz}]
$$

The generator's rpm can be expressed as:

$$
r p m_{\text {generator }}=120 \frac{f(\mathrm{~Hz})}{n}
$$

Increasing the number of poles $\mathrm{n}$ in a generator to 160 to produce $60 \mathrm{~Hz}$ electricity allows it to rotate at a smaller rpm value of:

$$
r p m_{\text {generator }}=120 \frac{60}{160}=45
$$

The gearing ratio, G, is defined in Eqn. 7 .

$$
G=\frac{r p m_{\text {generator }}}{r p m_{\text {rotor blade }}}
$$

Using the example of producing electricity at a frequency of $60 \mathrm{~Hz}$ with a 4-pole generator and a rotor blade operating at $15 \mathrm{rpm}$, Eqn. 7 shows that a gearing ratio G of :

$$
G=\frac{1,800}{15}=120
$$

between the rotor blade shaft and the generator shaft would be required.

If however, a 160 pole generator is used, the gearing ratio drops to:

$$
G=\frac{45}{15}=3
$$


with all other values held constant.

Finally, a 400-pole generator operating on a rotor blade at $18 \mathrm{rpm}$ would yield a gearing ratio of:

$$
\begin{aligned}
& r p m_{\text {generator }}=120 \frac{60}{400}=18 \\
& G=\frac{18}{18}=1
\end{aligned}
$$

A gearing ratio of unity implies that a gearbox would not be needed.

The first entrant with a direct-drive wind turbine is widely cited as being Enercon $\mathrm{GmbH}$ of Aurich, Germany. They suggest that their annular generator, in addition to precluding the need for a gearbox, contains a smaller number of moving parts, further contributing the increased reliability and reduction in frictional losses. Because the operational speeds of the generator are much lower, the generator is subjected to little, if any, wear, allowing to achieve a longer operational life and to handle larger loads.

Unique to Enercon, is their manual winding of the copper wire in the stator portion of the annular generator, justified by their use of a continuous wire strand in each generator, which reduces resistive losses. Enercon is very proud of their closed varnish-insulated wires, rated to Temperature Tolerance Class $\mathrm{F}\left(155^{\circ} \mathrm{F}\right)$, suggesting that breaks in the insulation, especially at joint locations, may have been a significant problem in early generator construction. In order to maintain high levels of quality control, Enercon manufactures its annular generators in the company's own production facilities.

Beginning with their first direct-drive wind turbine in 1993, Enercon has dominated the direct-drive wind turbine market, and in 2007 was fourth in terms of worldwide wind turbine market share, capturing 14 percent of the market behind Vestas, GE, and Gamesa. While in the past a number of competitors in the direct-drive market have filed for bankruptcy or been bought and sold repeatedly, as was the case for Lagerwey being sold to Zephyros which was sold to Harakosan, and then ended up in the hands of STX heavy Industries of Korea, the marketplace appears to have settled with the entrance of industry giants GE and Siemens. Figures 4 and 5 show annular generators under assembly at the Enercon's company manufacturing facilities.

One requirement for a direct-drive wind turbine is to not have direct coupling with the electrical grid. This is due to the fact that wind turbine rotor blades operate within an rpm range, and with a direct-coupled generator, the output voltage and frequency vary slightly. A DC link and inverter convert the produced energy to parameters suitable for transmission to the electrical grid. Prior to the development of these active electronic systems, wind turbines used capacitors and static Volt-Ampère-Reactive (VAR) systems that were far from optimal.

Another consideration of direct-drive wind turbines is their increased manufacturing and material costs. When the German company Siemens embarked on a two-year testing program for its 3.6 MW direct-drive turbine, Henrik Stiesdal commented that direct-drive wind turbines may become competitive with their geared counterparts near the upper end of turbine sizes (at that time in the 4-6 MW range), and with the test rigs they determined at what level direct-drive could be made competitive (Ragheb \& Ragheb, 2010). Three years later, these comments turned out to be almost prophetic, as the majority of the wind turbine designs with rated powers around 1.5 MW still utilize a planetary gear system, while the 


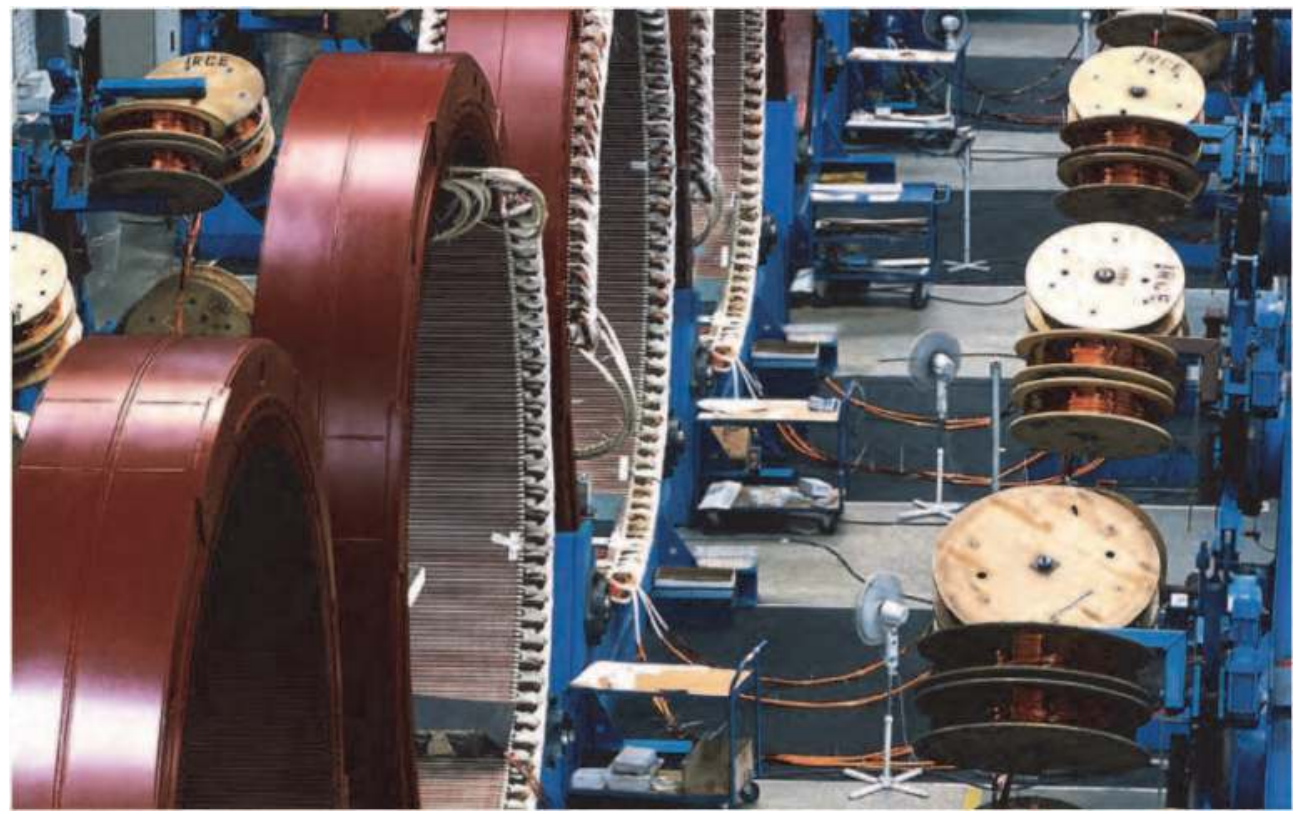

Fig. 4. Multipole annular generators under assembly (Photo: Enercon).

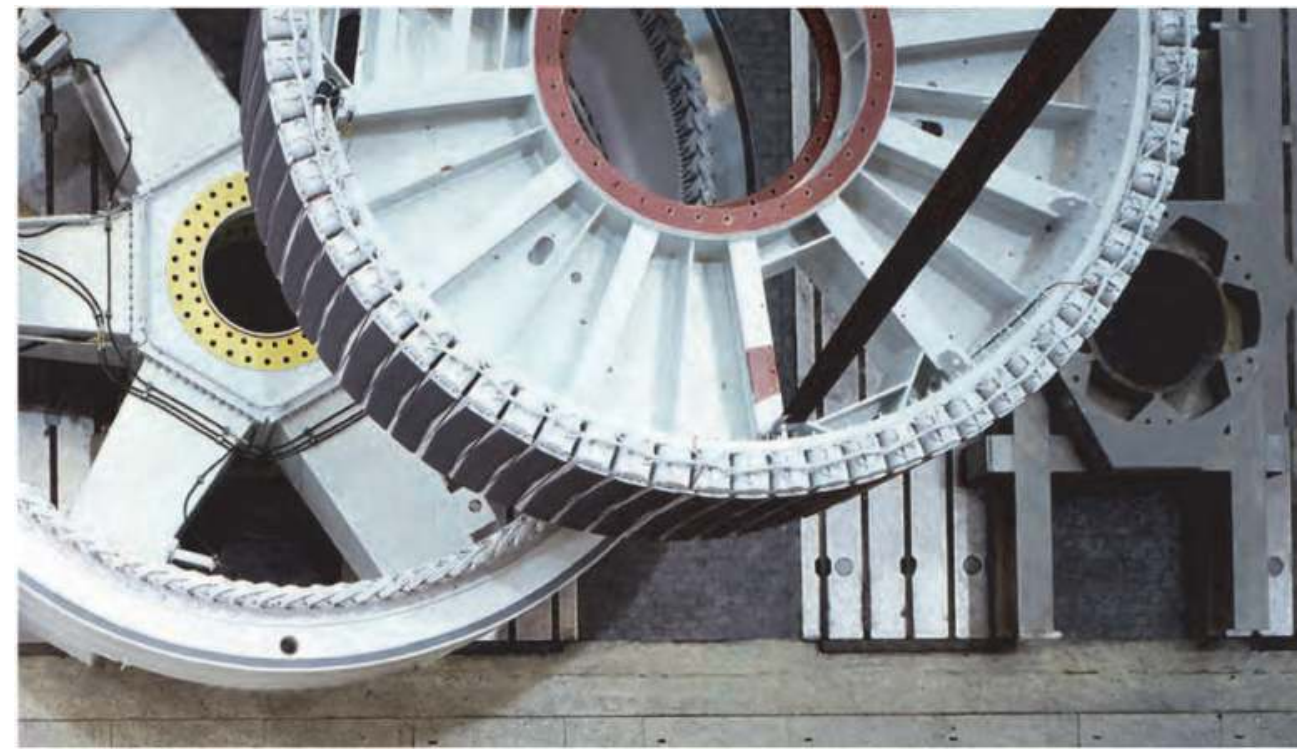

Fig. 5. Rotor and stator of Enercon E-70 wind turbine (Photo: Enercon). 
more recent and larger designs, many of which are marketed for offshore applications, are designed around direct-drive generators. It appears that this changeover point between geared and direct-drive wind turbines lies in the 1.5-3 MW rated power range.

According to the United States Department of Energy, direct-drive generators require large diameters, which necessitates the use of large amounts of rare earth elements magnets, and consequently are expensive and require a larger and heavier drivetrain. In addition to this, a small air gap on the millimeter scale is required to be maintained between the rotor and stator to yield sufficiently high flux densities. As a consequence, the tight manufacturing tolerances required and the detailed design to handle the complex loads encountered add another set of challenges that may set an upper limit on the size of such generators (Department of Energy, 2010).

While it was the first, Enercon is not the only company marketing direct-drive wind turbines. Japan Steel Works (JSW) has licensed Enercon's technology, and competes against the likes of Vensys, Leitwind, MTorres, and ScanWind, now acquired by General Electric (GE). Table 1 presents a summary of some of the utility scale direct-drive wind turbines designs currently available.

In late 2009, GE acquired ScanWind for approximately 15 million Euros in what appeared to be a technology-driven move to reenter the offshore wind turbine sector. GE's previous foray into offshore wind turbines was the Arklow Bank Wind Park (Ireland) project, in which seven 3.6 MW technology demonstrator wind turbines were installed. In contrast to the ScanWind direct-drive turbines, these wind turbines utilized a three step planetary gear system.

The direct-drive approach to the gearbox problem appears to be taking hold quite well on the largest capacity wind turbines. Due to its lower amount of moving parts, it seems ideally suited for large offshore applications.

Direct-drive may not however solve the existing gearbox problems for all wind turbines over the rated power range between 1.5 and $10 \mathrm{MW}$, as it brings with it weight increases of around 25 percent and a cost increase of around 30 percent.

A further development of the direct-drive solution couples a direct-drive concept with superconducting materials, with potential benefits being reduced mass and volume, and consequently smaller transportation costs and lower loadings on the tower. Cost advantages of superconducting direct-drive generators will most likely not exist for turbines below a rated power of $5 \mathrm{MW}$, but with turbines of $10 \mathrm{MW}$ already being constructed for offshore use, this drivetrain concept may soon become a reality (Department of Energy, 2010).

\section{Torque splitting}

A different attempt at solving the gearbox problem on 2+ MW sized wind turbines was undertaken by Clipper Windpower of Carpineria, California. Under a partnership with the United States Department of Energy (DOE) and the National Renewable Energy Laboratory (NREL), Clipper developed their 2.5 MW Liberty Wind Turbine, the largest manufactured in the United States. These turbines, manufactured in 2006, were put into service in early 2007 as part of the Steel Winds Project, a superfund location along Lake Erie in Lackawana, New York, and the company received a DOE Outstanding Research and Development Partnership Award in 2007. After only a few months of service, problems were observed in their distributed gearing-style gearboxes. A subsequent analysis traced the fault to improper drivetrain timing caused by incorrect gear tolerances on parts arriving from suppliers (Robb, 2008). 


\begin{tabular}{|c|c|c|c|}
\hline Company & Country & $\begin{array}{c}\text { Turbine Rated } \\
\text { Power (MW) }\end{array}$ & $\begin{array}{c}\text { Rotor blade } \\
\text { Diameter }(\mathrm{m})\end{array}$ \\
\hline $\begin{array}{l}\text { Clipper [Windpower] Marine } \\
\text { deployment date: } 2012\end{array}$ & UK & 10 & 144 \\
\hline Sway & Norway & 10 & 145 \\
\hline Enercon E-126 & Germany & 7.5 & 127 \\
\hline Nordex N150/6000 & Germany & 6.0 & 150 \\
\hline $\begin{array}{l}\text { Xingtan Electric Manufacturing } \\
\text { Corporation }\end{array}$ & China & 5.0 & - \\
\hline GE 4.1-113 & United States & 4.1 & 113 \\
\hline GE $4.0-110$ & United States & 4.0 & 110 \\
\hline $\begin{array}{l}\text { ScanWind } 3.5 \text { (evolved into GE } 4 . X \\
\text { series) }\end{array}$ & Norway & 3.5 & 90 \\
\hline Enercon E-101 & Germany & 3.0 & 101 \\
\hline Leitwind LTW101 & Italy & 3.0 & 101 \\
\hline Siemens SWT 3.0-101 & Germany & 3.0 & 101 \\
\hline Enercon E-82 & Germany & $2.0-3.0$ & 83 \\
\hline $\begin{array}{l}\text { Guangxi Yinhe Avantis Wind Power } \\
\text { (in testing) }\end{array}$ & China & 2.5 & - \\
\hline Vensys $2.5 \mathrm{MW}$ & Germany & 2.5 & $90-100$ \\
\hline Enercon E-70 & Germany & 2.3 & 71 \\
\hline Leitwind LTW70 & Italy & $1.7-2.0$ & 70.1 \\
\hline Leitwind LTW80 & Italy & $1.5-1.8$ & 80.3 \\
\hline MTorres TWT 1.65/70 & Spain & 1.65 & 70 \\
\hline MTorres TWT 1.65/77 & Spain & 1.65 & 77 \\
\hline MTorres TWT 1.65/82 & Spain & 1.65 & 82 \\
\hline Leitwind LTW77 & Italy & 1.5 & 76.6 \\
\hline Leitwind LTW86 & Italy & 1.5 & 86.3 \\
\hline Vensys 1.5 MW & Germany & 1.5 & $70-82$ \\
\hline
\end{tabular}

Table 1. Direct-drive wind turbine rated power (MW) and rotor blade diameters. 


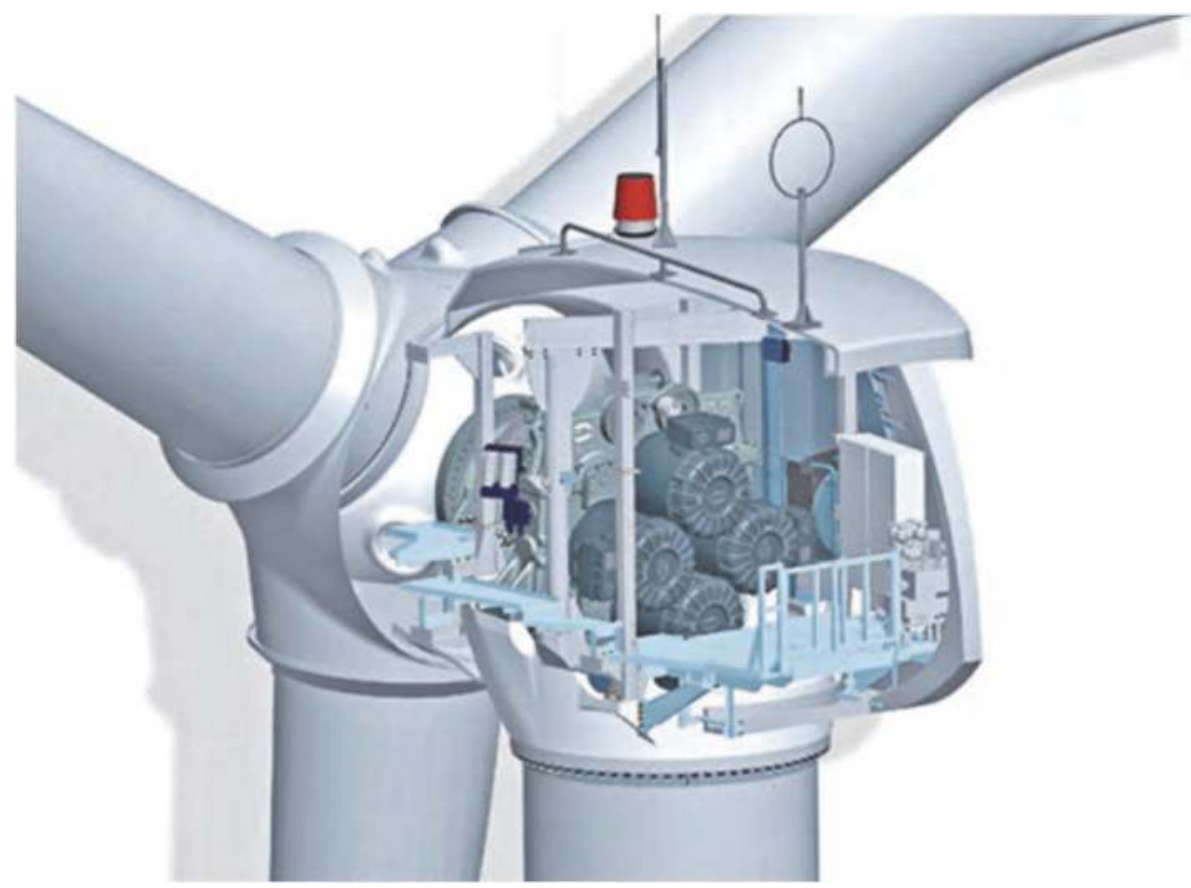

Fig. 6. Torque splitting between four electrical generators on the 2.5 MW Clipper Liberty (Image: Clipper Windpower).

Using its patented Quantum Drive Distributed Generation Powertrain, the 2.5 MW Liberty wind turbine uses a multiple-path gearbox design to split the torque from its 89-99 meter rotor blades evenly between four generators that are operated in parallel. In contrast to a planetary gearing system, Clipper utilizes external double helical gears in order to allow for wide faces with their lower deflection sensitivities, smaller diameters, and reduced manufacturing costs due to lower required tolerances. The gear set for each of the generators is designed in "cartridge" form so as to allow for replacement without requiring the removal of the gearbox. Additionally, if a fault were to develop in one of the generators or cartridged gear sets, the production capacity of the wind turbine is reduced by only 25 percent until the problem can be corrected (Mikhail \& Hahlbeck, 2006).

After selling 370 turbines in 2006, and 825 in 2007, the company appeared to have recovered from their early quality control problems. Clipper Wind was acquired in December 2010 by United Technologies Corporation. On March 24, 2011, Clipper Wind dedicated the first large-scale wind farm on the island of Oahu, which consists of $122.5 \mathrm{MW}$ wind turbines coupled to a $15 \mathrm{MW}$ batter storage system to smooth power output fluctuations. This project was developed by the Boston-based First Wind, one of Clipper Windpower's long standing customers. As of early 2011, a total of 375 Clipper Windpower turbines are featured in 17 projects across the US, with a cumulative rated power of $938 \mathrm{MW}$.

Torque splitting appears to be a cheaper alternative to the direct-drive solution, although it appears that the upper viable limit of torque splitting may lie below that of direct-drive machines. 
In addition to Clipper Windpower, CWind of Ontario, Canada is introducing a $2 \mathrm{MW}, 8$ generator wind turbine design. They were testing a $65 \mathrm{~kW}$ wind turbine, and have announced plans to develop a 7.5 MW turbine. Their design concept may be a hybrid between torque splitting and a Continuously Variable Transmission (CVT), as they allude to a "friction drive system" to absorb sudden wind spikes. A frictional contact drive is one of the many types of CVTs. Finally, it should be noted that as shown in Table 1, the subsidiary of Clipper Windpower, Clipper Marine, has opted for a direct-drive system on its $10 \mathrm{MW}$ turbine. This may provide clues as to the maximum economical size for a wind turbine built around a torque splitting concept.

\section{Magnetic bearings}

A very promising potential solution to the shaft misalignment problem may come from the aerospace and centrifuge uranium enrichment industries in the form of magnetic bearings or Active Magnetic Bearings (AMBs).

Recent research by NASA, MTU and others point to research in the area of high temperature magnetic bearings for use in gas turbine engines to propel aircraft. What appears to be the next large leap in terms of powering commercial transport aircraft is the Geared Turbofan (GTF) engine, which is slated to power the Mitsubishi MRJ, Bombarider C-Series, and A320neo, and may serve as the platform on which AMBs may be used in aerospace applications. An AMB system consists of a magnetic shaft, a controller, multiple electromagnetic coils attached to a stator shaft location as shown in Fig. 7. In the event of a failure of the control system, AMBs typically have a passive backup bearing system, which defaults to a rolling element bearing for the "limp home" operational mode sensors (Clark et al., 2004).

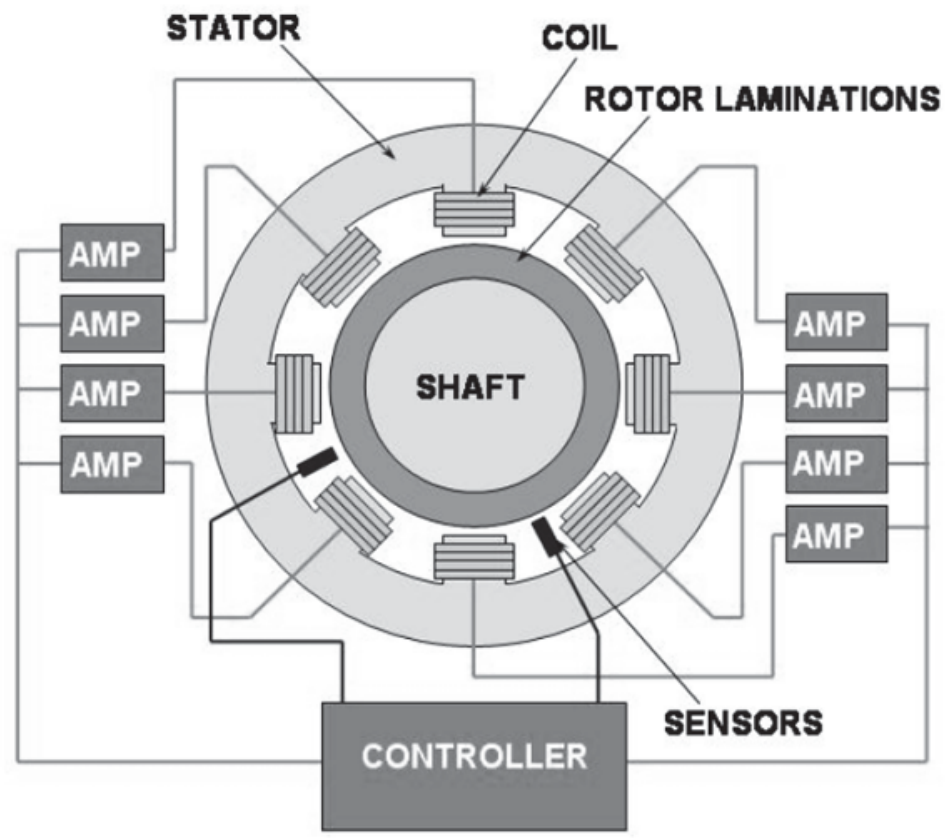

Fig. 7. Schematic of an Active Magnetic Bearing (Clark et al., 2004). 
The GTF engine is by no means a new concept, as engine maker Pratt and Whitney understood the theoretical justification behind the concept in the early 1980s. The level of technology and materials development necessary to meet the stringent safety, reliability, and ruggedness requirements of modern gas turbine engines has been achieved lately. The Pratt and Whitney company suggests that through thousands of hours of development, advances in bearing, gear system, and lubrication design have been made and incorporated into their new family of GTFs, with initial reports suggesting promising heat and efficiency data.

SAE International reports that Pratt and Whitney uses a self-centering bearing technology that has all but eliminated the problems of gear misalignment and stress in the gearbox of the PW8000 GTF. It seems to be more likely that this has been achieved through their patented squirrel-cage bearing (Kostka, 2010), but based on the high temperature tolerance of AMBs, a magnetic bearing in a gas turbine engine does not appear to be too far off.

The use of magnetic bearings for gas turbine engines has been studied in depth, and papers on the topic point out a number of their potential benefits, as well as their shortcomings. Benefits of magnetic bearings include durability and damage tolerance (Clark et al., 2004), much smaller frictional losses (Schweitzer, 2002), and increased reliability at a reduced weight. Magnetic bearings also offer the potential to eliminate lubricating oil systems and avoid bearing wear, and have already demonstrated their successful application in machine spindles, mid-sized turbomachinery, and large centrifugal compressors (Becker, 2010). Eliminating the oil system in a wind tunnel gearbox provides a very large potential benefit, as numerous wind turbine fires have been attributed to the oil in an overheated gearbox catching fire. Figure 8 is a photograph of one of many wind turbines whose overheated gearboxes caused the lubricating oil to catch fire.

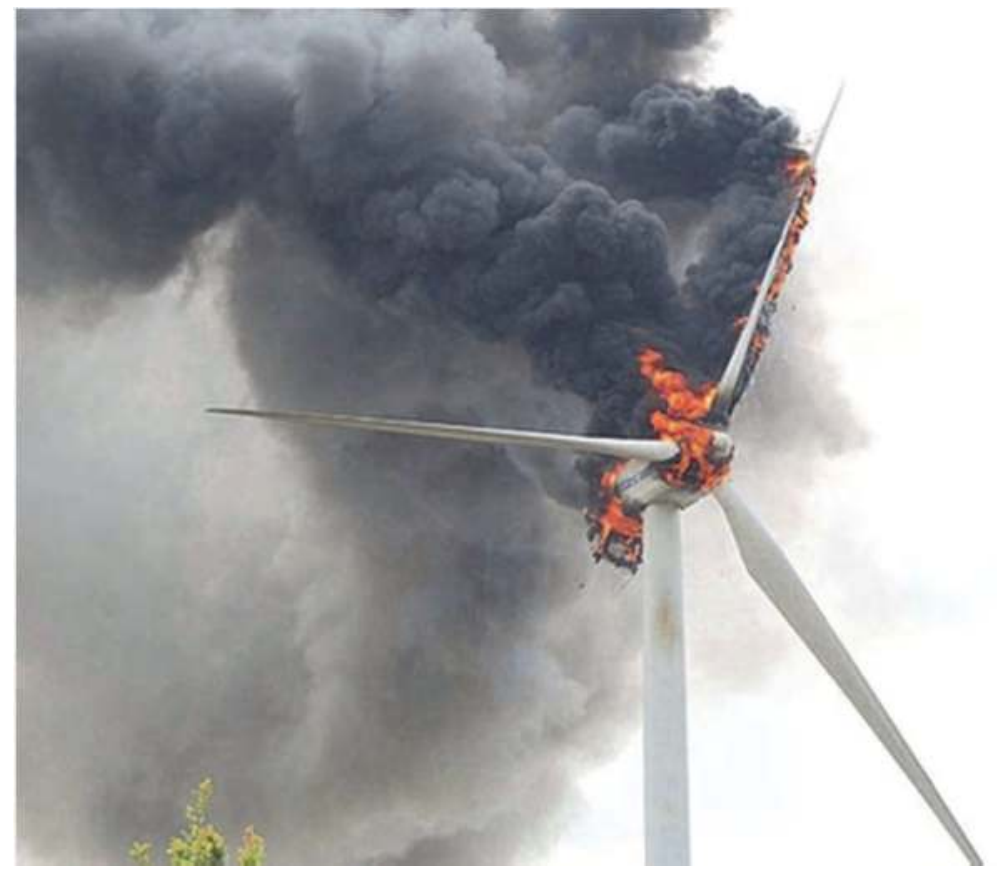

Fig. 8. A utility scale wind turbine on fire (Photo: flickr). 
Rolling element bearings, currently used in wind turbines, are hindered by their relatively short lifetime when subjected to high loads. Both foil and magnetic bearings offer longer lifetimes, with magnetic bearings outperforming foil bearings when used in large rotating machinery under high loads and a relatively low speed (Clark, 2004). Large, heavily loaded, and relatively slow rotating provides a nearly perfect description of a modern utility scale wind turbine generator.

A common criticism of magnetic bearings is the high power requirement to generate ample current to generate a magnetic field great enough to yield an ample magnetic force to handle the large loads. This criticism is simply outdated, as recent advances in permanent magnets allow similarly strong magnetic fields to be generated by said magnets instead of via a current. It is these same permanent magnet advances that have allowed the construction of the aforementioned direct-drive generators.

Magnetic bearings appear well-poised to mitigate some of the current gearbox problems, but their application to wind turbines lies well behind the current state of development of direct-drive and torque splitting solutions. This solution has the potential to aid in the solution of gearbox problems on the lower end of utility scale wind turbines, as it may be adaptable to existing gearbox designs with minimal design changes required. As the technology matures, magnetic bearings have the potential to allow conventional gearbox designs to approach turbine rated powers of as much as $4 \mathrm{MW}$, if specific design constraints call for the use of a conventional gearbox.

\section{Continuously Variable Transmissions, CVTs}

Another option for solving the gearbox problem is the use of a Continuously Variable Transmission (CVT). This gearing design has only recently reached mass production in passenger vehicles, although it has been in use for a long time on farm machinery, drill presses, snowmobiles, and garden tractors. Transmissions of the CVT type are capable of varying continuously through an infinite number of gearing ratios in contrast to the discrete varying between a set number of specific gear ratios of a standard gearbox.

It is this gearing flexibility that allows the output shaft, connected to the generator in wind turbine applications, to maintain a constant rate of rotation for varying input angular velocities. The variability of wind speed and the corresponding variation in the rotor rpm combined with the fixed phase and frequency requirements for electricity to be transmitted to the electrical grid make it seem that CVTs in concert with a proportional Position, Integral, Derivative (PID) controller have the potential to significantly increase the efficiency and cost-effectiveness of wind turbines.

One disadvantage of CVTs is that their ability to handle torques is limited by the strength of the transmission medium and the friction between said medium and the source pulley. Through the use of state of the art lubricants, the chain-drive type of CVT has been able to adequately serve any amount of torque experienced on buses, heavy trucks, and earthmoving equipment. In fact, the Gear Chain Industrial B.V. Company of Japan appears to have initiated work on a wind application for chain-driven CVTs.

In addition to being able to handle minor shaft misalignments without being damaged, CVTs offer two additional potential benefits to wind turbines. As reported by Mangliardi and Mantriota $(1996,1994)$, a CVT-equipped wind turbine is able to operate at a more ideal tip speed ratio in a variable speed wind environment by following the large fluctuations in the wind speed. When simulated in a steady wind stream, a power increase with the 
addition of a CVT was observed for wind speeds above $11 \mathrm{~m} / \mathrm{s}$, and at $17 \mathrm{~m} / \mathrm{s}$, the CVTequipped turbine power was double that of a conventional configuration, while exhibiting only a 20 percent increase in torque. These results suggest that the typical cut-out wind speed of $25 \mathrm{~m} / \mathrm{s}$, set to limit the shaft stress and other stresses, may possibly be reevaluated, to reflect the lower shaft stresses and higher rotor efficiencies at higher wind speeds (Mangliardi \& Mantriota, 1994). The dynamic results were even more promising, as a CVTequipped turbine subjected to a turbulent wind condition demonstrated increased efficiencies of on average 10 percent relative to the steady wind stream CVT example. Additionally, the CVT-equipped turbine simulation produced higher quality electrical energy, as the inertia of the rotor helped to significantly reduce the surges that are everpresent in constant-speed wind turbines subjected to rapid changes in wind speed (Mangliardi \& Mantriota, 1996). Mangliardi and Mantriota go on to determine the extraction efficiency of a CVT-equipped and a CVT-less wind turbine as a function of wind speed, and this is presented below in Fig. 9.

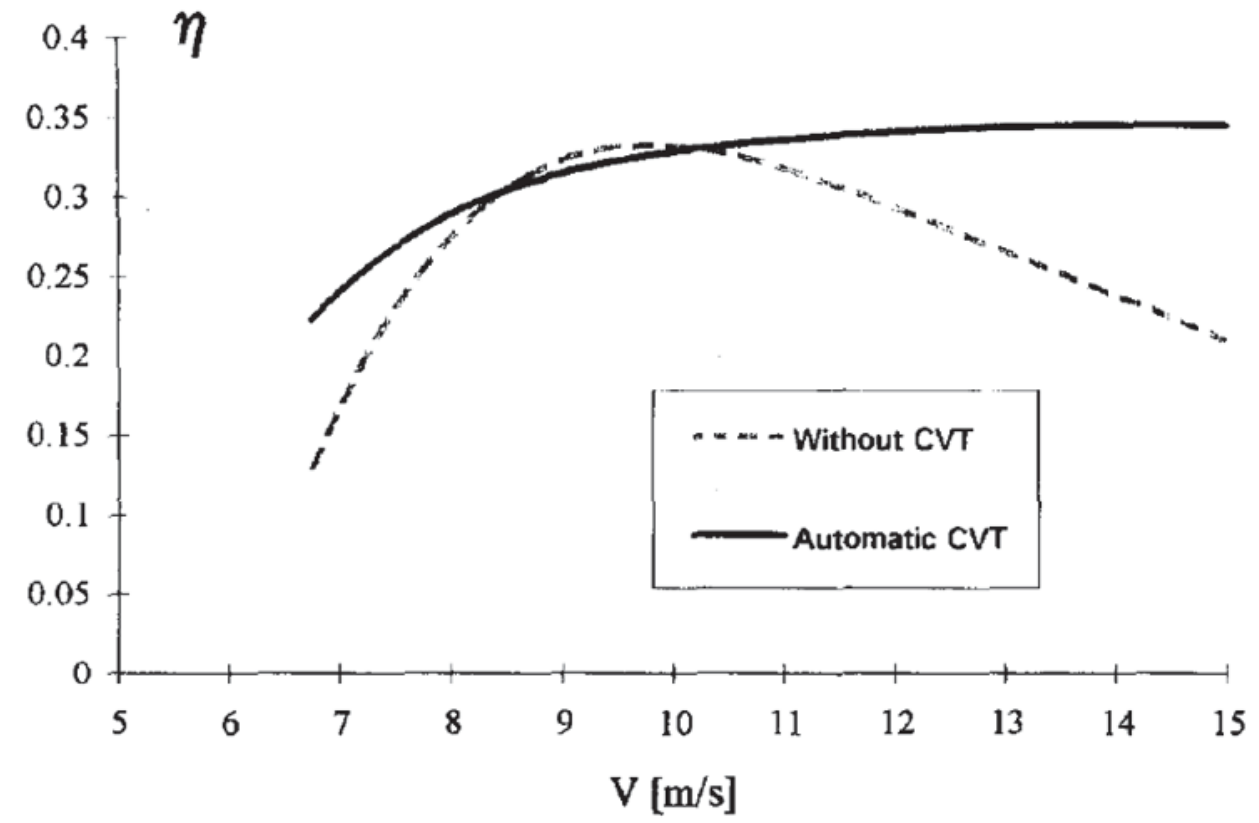

Fig. 9. Extraction efficiency $\eta$ of standard and CVT-equipped wind turbines as a function of wind speed in a turbulent wind field (Mangliardi and Mantriota, 1996).

As observable in Fig. 9, a CVT-equipped wind turbine is more efficient than a conventional wind turbine at extracting the energy of the wind over all but a narrow range of wind speeds. The wind speed range where the CVT-equipped turbine is at a disadvantage is centered on the design point of the conventional wind turbine, where both turbines exhibit similar aerodynamic efficiencies, but the CVT-equipped turbine is hampered by energy losses in its gearing system. It should be noted that this is a rather narrow range, and the value by which the CVT wind turbine trails the conventional wind turbine is much smaller when compared to its benefits over the rest of the range of wind speeds. 
As one moves from an ideal constant and uniform wind field to a turbulent wind field, the potential benefits of a CVT-equipped wind turbine increase. The ratio of efficiency of a CVT wind turbine to a conventional one, $\mathrm{R}_{\mathrm{n}}$, increases (Mangliardi and Mantriota, 1996).

Potential challenges to turbines equipped with a CVT center mainly on the lack of knowledge about the scalability of such designs. Questions such as what is the upper limit to the amount of torque that may be transmitted through a belt drive have yet to be answered. The potential benefits exist, but it appears that more research and turbine test platforms are needed before the range of applicability of CVTs on wind turbines is known (Department of Energy, 2010) and their commercial benefits quantified. Hydrostatic drives are one type of CVT that has been studied for wind turbine applications, but it appears, at least initially, that this may replace one problem, gearbox oil filtration, with another, increased maintenance and hydraulic fluid cleanliness requirements.

\section{Discussion}

According to Fig. 10, gearbox failures account to 5 percent of wind turbine failures. However, they are costly compared with the other failures when they occur.

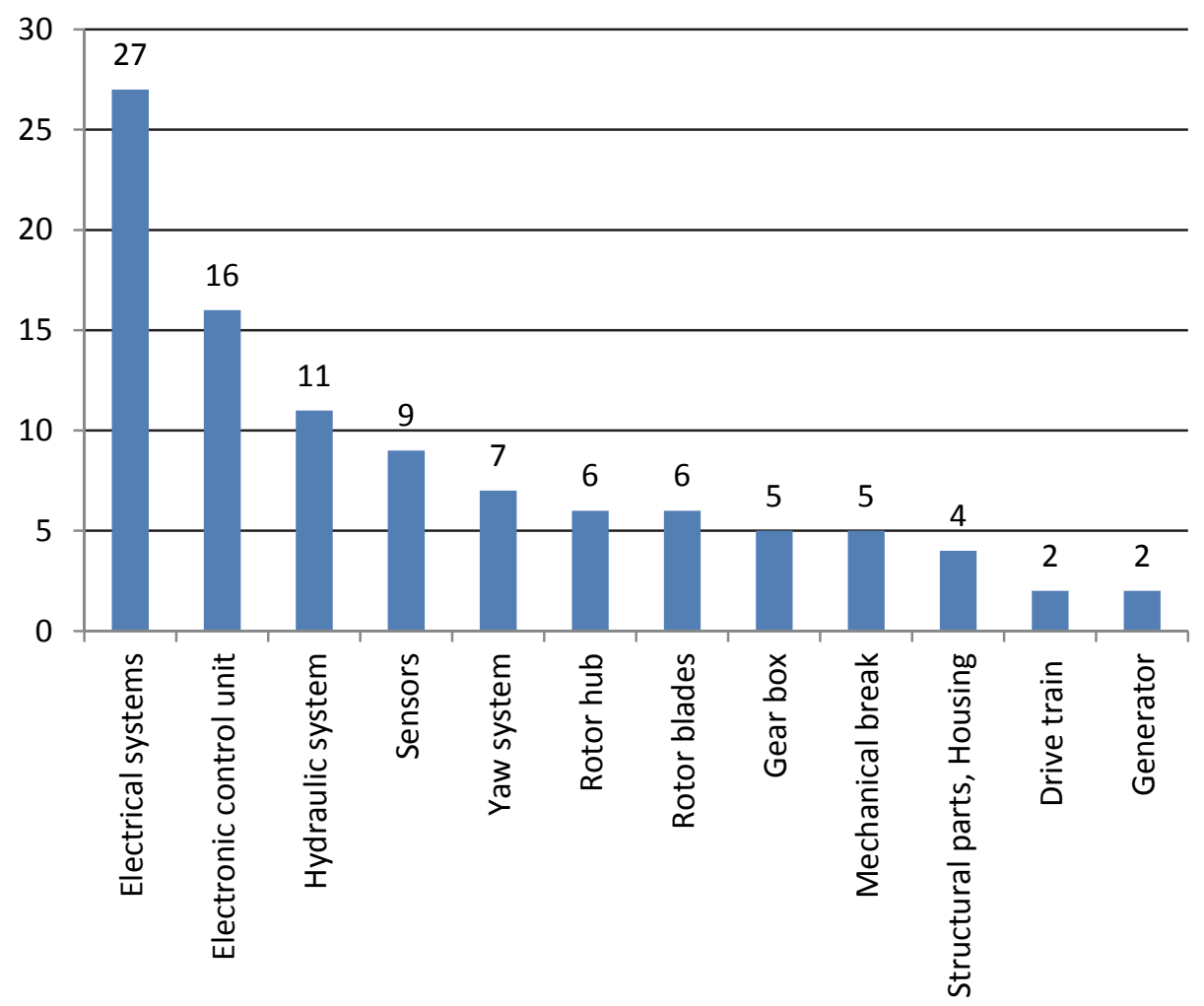

Fig. 10. Percentage of needed repairs and maintenance on utility scale wind turbines. Data: AWEA. 
While wind turbines are designed for a lifetime of around 20 years, existing gearboxes have exhibited failures after about 5 years of operation. The costs associated with securing a crane large enough to replace the gearbox and the long downtimes associated with such a repair affect the operational profitability of wind turbines. A simple gearbox replacement on a 1.5 MW wind turbine may cost the operator over \$250,000 (Rensselar, 2010). The replacement of a gearbox accounts for about 10 percent of the construction and installation cost of the wind turbine, and will negatively affect the estimated income from a wind turbine (Kaiser \& Fröhlingsdorf, 2007).

Additionally, fires may be started by the oil in an overheated gearbox. The gusty nature of the wind is what degrades the gearbox, and this is unavoidable.

Figure 11 summarizes the estimates of the economic rated power ranges of applicability for each of the considered wind turbine gearbox solutions.

The direct-drive approach to the current wind turbine gearbox reliability problem seems to be taking a strong hold in the $3 \mathrm{MW}$ and larger market segment, although torque splitting is also being used in this range.

For the 1.5 to $3 \mathrm{MW}$ range however, multiple viable options exist or show potential, including torque splitting, magnetic bearings, and Continuously Variable Transmissions (CVTs). These options may gain traction over direct-drive solutions due to the approximately 30 percent cost premium of a direct-drive system, and the larger sizes and capital costs associated with such a system.

If the magnetic bearing route is to be used, the answer may lie with gas turbine manufacturers, as their design criteria already call for bearings that are highly reliable, damage tolerant, and capable of handling large loads. CVTs appear to also offer aerodynamic efficiency benefits

\section{Direct-Drive}

\section{Torque Splitting}

\section{Magnetic Bearings}

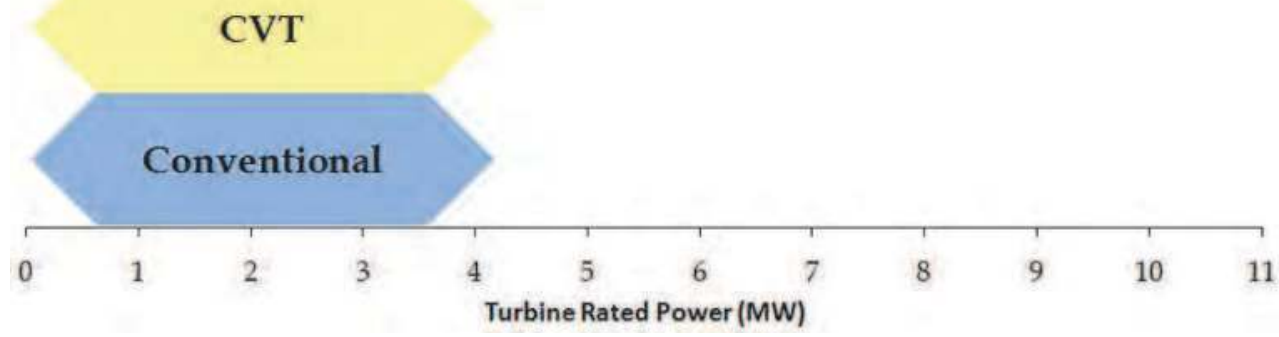

Fig. 11. Identified rated power applicability ranges of existing and possible wind turbine gearbox options. CVT: Continuously Variable Transmission. 
to wind turbines, but they may be limited by the amount of torque that may be transmitted by chain, belt, or hydrostatic means. For this reason, magnetic bearings appear to provide a potential solution to a slightly wider range of turbine rated powers than CVTs would.

\section{References}

Becker, K.H. (2010) Magnetic Bearings for Smart Aero Engines (MAGFLY). Proceedings of the $13^{\text {th }}$ International Symposium on Transport Phenomena and Dynamics of Rotating Machinery (ISROMAC-13), G4RD-CT-2001-00625, Honolulu, Hawaii, April 2010.

Burton, T., Sharpe, D, Jenkins, N, Bossany, E. (2004). Wind Energy Handbook (3 ${ }^{\text {rd }}$ Ed.). John Wiley \& Sons Ltd., ISBN: 0-471-48997-2, West Sussex, England.

Clark, D.J. Jansen, M.J., Montague, G.T. (2004). An Overview of Magnetic Bearing Technology for Gas Turbine Engines. National Aeronautics and Space Administration, NASA/TM-2004-213177.

Department of Energy (2010). Advanced Wind Turbine Drivetrain Concepts: Workshop Report. Key Findings from the Advanced Drivetrain Workshop, Broomfield, Colorado, June 2010.

Enercon (2010). Enercon Wind Energy Converters: Technology \& Service. Available from: <http://www.enercon.de/p/downloads/EN_Eng_TandS_0710.pdf>

Kaiser, S., Fröhlingsdorf, M. (August 20, 2007). The Dangers of Wind Power, In: Spiegel Online, May 2010, Available from:

<http://www.spiegel.de/international/germany/0,1518,500902,00.html>

Kostka, R.A., Kenawy, N. Compact Bearing Support. United States Patent Number 7,857,519. Issued December 28, 2010.

Musial, W. Butterfield, S., McNiff, B. (2007). Improving Wind Turbine Gearbox Reliability, Proceedings of the 2007 European Wind Energy Conference, NREL: CP-500-41548, Milan, Italy, May 2007.

Mangliardi, L, Mantriota, G. (1994). Automatically Regulated C.V.T. in Wind Power Systems. Renewable Energy, Vol. 4, No. 3, (1994), pp. 299-310, 0960-1481(93)E0004-B.

Mangliardi, L., Mantriota, G. (1996). Dynamic Behaviour of Wind Power Systems Equipped with Automatically Regulated Continuously Variable Transmission. Renewable Energy, Vol. 7, No. 2, (1996), pp. 185-203, 0960-1481(95)00125-5.

Mikhail, A.S., Hahlbeck, E.C. Distributed Power Train (DGD) With Multiple Power Paths. United States Patent Number 7,069,802. Issued July 4, 2006.

Ragheb A., Ragheb, M. (2010). Wind Turbine Gearbox Technologies, Proceedings of the $1^{\text {st }}$ International Nuclear and Renewable Energy Conference (INREC'10), ISBN: 978-1-42445213-2, Amman, Jordan, March 2010.

Rensselar, J. (2010). The Elephant in the Wind Turbine. Tribology \& Lubrication Technology, June 2010, pp.2-12.

Robb, D. "The Return of the Clipper Liberty Wind Turbine." Power: Business and Technology for the Global Generation Industry. (December 1, 2008)

Schweitzer, G. (2002). Active Magnetic Bearings - Chances and Limitations. Proceedings of the $6^{\text {th }}$ International Conference on Rotor Dynamics, Sydney Australia, September 2002. 


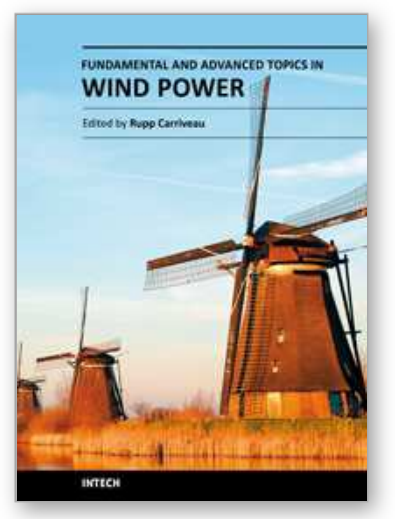

\author{
Fundamental and Advanced Topics in Wind Power \\ Edited by Dr. Rupp Carriveau
}

ISBN 978-953-307-508-2

Hard cover, 422 pages

Publisher InTech

Published online 20, June, 2011

Published in print edition June, 2011

As the fastest growing source of energy in the world, wind has a very important role to play in the global energy mix. This text covers a spectrum of leading edge topics critical to the rapidly evolving wind power industry. The reader is introduced to the fundamentals of wind energy aerodynamics; then essential structural, mechanical, and electrical subjects are discussed. The book is composed of three sections that include the Aerodynamics and Environmental Loading of Wind Turbines, Structural and Electromechanical Elements of Wind Power Conversion, and Wind Turbine Control and System Integration. In addition to the fundamental rudiments illustrated, the reader will be exposed to specialized applied and advanced topics including magnetic suspension bearing systems, structural health monitoring, and the optimized integration of wind power into micro and smart grids.

\title{
How to reference
}

In order to correctly reference this scholarly work, feel free to copy and paste the following:

Adam M. Ragheb and Magdi Ragheb (2011). Wind Turbine Gearbox Technologies, Fundamental and Advanced Topics in Wind Power, Dr. Rupp Carriveau (Ed.), ISBN: 978-953-307-508-2, InTech, Available from: http://www.intechopen.com/books/fundamental-and-advanced-topics-in-wind-power/wind-turbine-gearboxtechnologies

\section{INTECH}

open science | open minds

\author{
InTech Europe \\ University Campus STeP Ri \\ Slavka Krautzeka 83/A \\ 51000 Rijeka, Croatia \\ Phone: +385 (51) 770447 \\ Fax: +385 (51) 686166 \\ www.intechopen.com
}

\author{
InTech China \\ Unit 405, Office Block, Hotel Equatorial Shanghai \\ No.65, Yan An Road (West), Shanghai, 200040, China \\ 中国上海市延安西路65号上海国际贵都大饭店办公楼 405 单元 \\ Phone: +86-21-62489820 \\ Fax: +86-21-62489821
}


(C) 2011 The Author(s). Licensee IntechOpen. This chapter is distributed under the terms of the Creative Commons Attribution-NonCommercialShareAlike-3.0 License, which permits use, distribution and reproduction for non-commercial purposes, provided the original is properly cited and derivative works building on this content are distributed under the same license. 